\title{
Experimental Study on the Shear Strength of Trapezoidal Corrugated Steel Webs with Longitudinal Stiffeners
}

\author{
Guoqing Zhang \\ Hebei Provincial Communications Planning and Design Institute, China \\ hbqss@126.com
}

Keywords: trapezoidal corrugated steel webs; experimental research; shear strength; buckling strength; longitudinal stiffeners.

Abstract: The shear strength of trapezoidal corrugated steel webs is an important parameter for the design of girder bridges with trapezoidal corrugated steel webs. Five I-shaped steel beams with different longitudinal stiffeners were tested to preliminarily investigate the shear behavior of trapezoidal corrugated steel webs. In addition, the experimental results were compared with the results calculated with the theoretical formula. Furthermore, the shear strength of trapezoidal corrugated steel webs with different longitudinal stiffeners was compared and provided construction practice.

\section{Introduction}

The prestressed concrete composite girder bridge with corrugated steel webs is a new type of bridge structure which has been widely applied in domestic in recent years. In the girder with corrugated steel webs, bending moment is mainly undertaken by the top and bottom flange, and shear force is mainly undertaken by the corrugated steel webs, and the shear stress distributes uniformly along the direction of the web height ${ }^{[1]}$. Due to the mechanical properties of the prestressed concrete composite girder with corrugated steel webs, the calculation of shear strength of corrugated steel webs is an important issue in the shear design.

In this paper, five I-shaped steel beams with different longitudinal stiffeners experimental study of shear strength were conducted to provide experimental basis and data foundation. The theoretical formulas for local elastic shear buckling strength and global elastic shear buckling strength were used to calculate the shear strength of trapezoidal corrugated steel webs. The five different longitudinal stiffeners change the mechanical characteristics and reinforce the shear strength which provides construction practice.

\section{Experimental Situation}

Five I-shaped steel beams with different longitudinal stiffeners are shown in Fig. 1- Fig. 5. (Note: The web thickness is $2.5 \mathrm{~mm}$, Numbers in figures are in millimeter.)

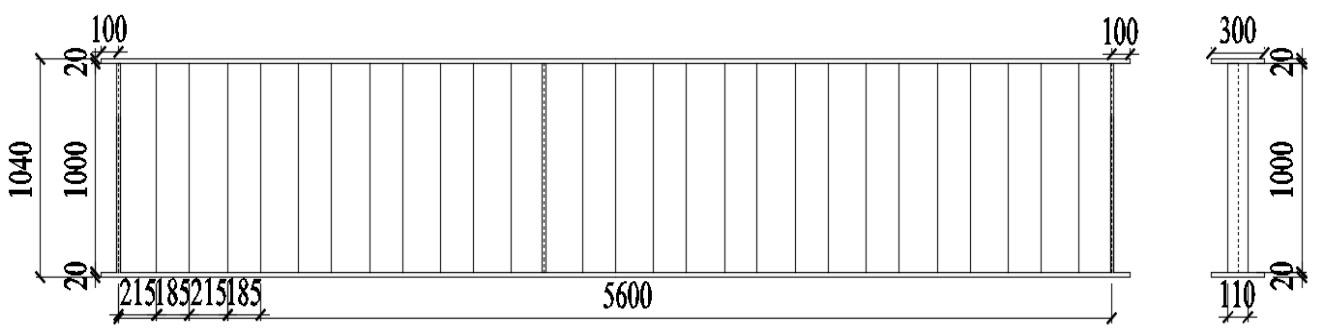

Fig. 1 Dimension of I-shaped beam with corrugated steel web (GCW) 


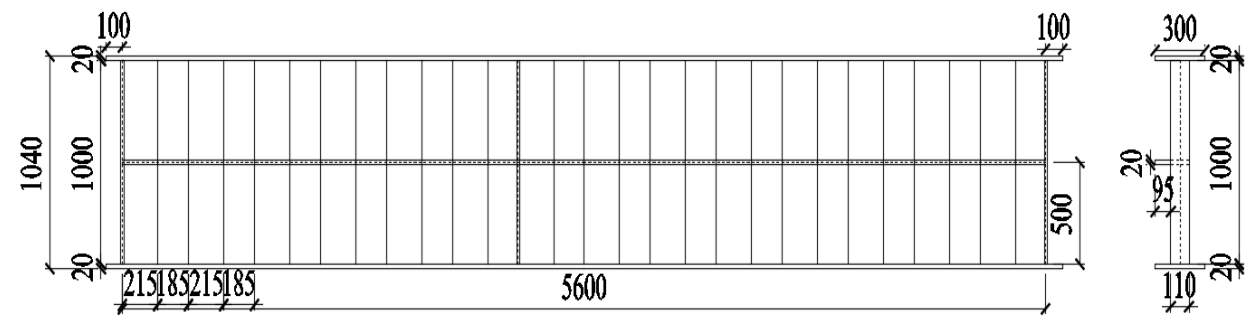

Fig. 2 Dimension of corrugated steel web with one longitudinal stiffener (SGCW1)

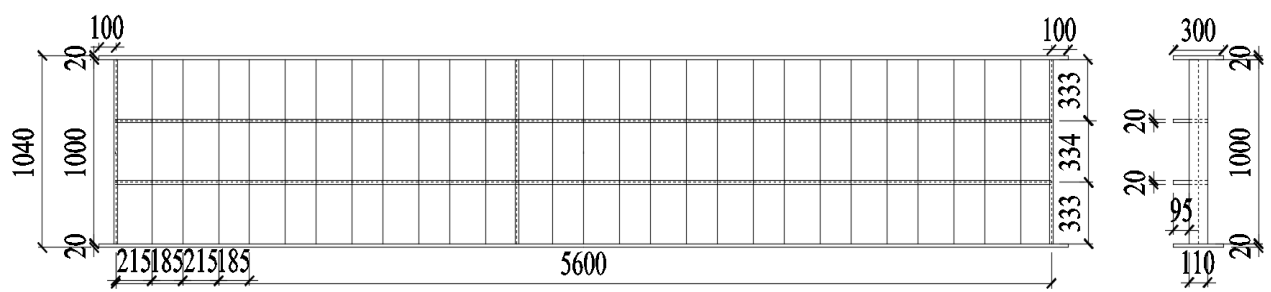

Fig. 3 Dimension of corrugated steel web with two longitudinal stiffeners (SGCW2)

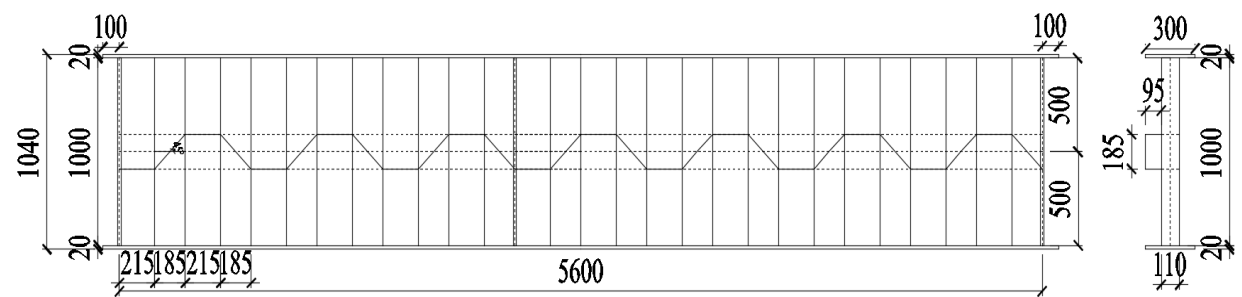

Fig. 4 Dimension of corrugated steel web with one corrugated longitudinal stiffener (CSGCW1)

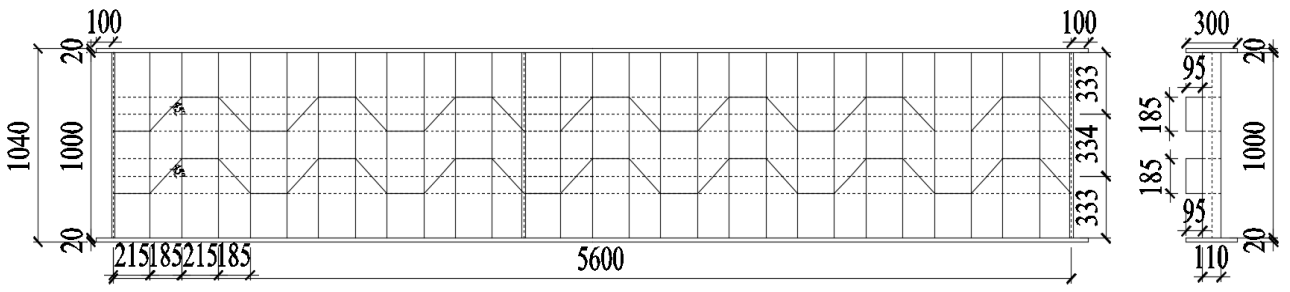

Fig. 5 Dimension of corrugated steel web with two corrugated longitudinal stiffeners (CSGCW2)

The loading device was composed of the pedestal and a hydraulic jack, a single point load was applied to all specimens and controlled by loading force, Figure. 6 shows both the beam loading pattern and the location of the strain gauges and rosettes and the displacement meters.

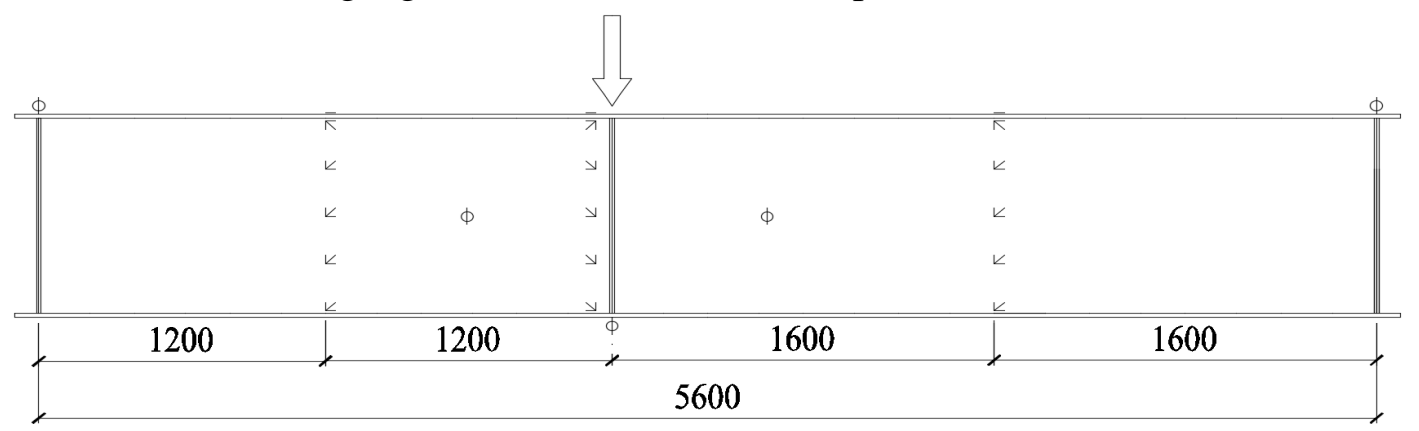

Fig. 6 Main measurement point arrangement of specimens

The test purpose of main measurement point:

(1) Longitudinal strain gauges were used to measure the normal strain of the beam;

(2) Strain rosettes in height direction were used to measure the shear stress of the web;

(3) Displacement meters under the bottom plate were used to measure the load-deflection curve;

(4) Displacement meters out of plane were used to measure the deflection of the web; 


\section{Experimental Process and Phenomenon}

Five I-shaped steel beams were loaded in same process and controlled by loading force. Failure mode of specimens were all buckling failure in the webs. When the loading force came to $60 \mathrm{kN}$ or $80 \mathrm{kN}$, the beams were in linear elastic stage, there was no obvious deflection of the web. The loading force was added gradually, the webs occurred micro drum phenomenon. Then, the webs began buckling at 45 degree from the direction of the beam axis. With the increase of loading force, this buckling phenomenon was more and more obvious. The buckling developed throughout the webs of the short span. Finally the beams were affected and lost bearing capacity. The failure mode ${ }^{[2]}$ of CSGCW2 was different with others, the local buckling occurred in one of the folded plate. Fig. 7 shows and Table 1 lists the failure mode of specimens.

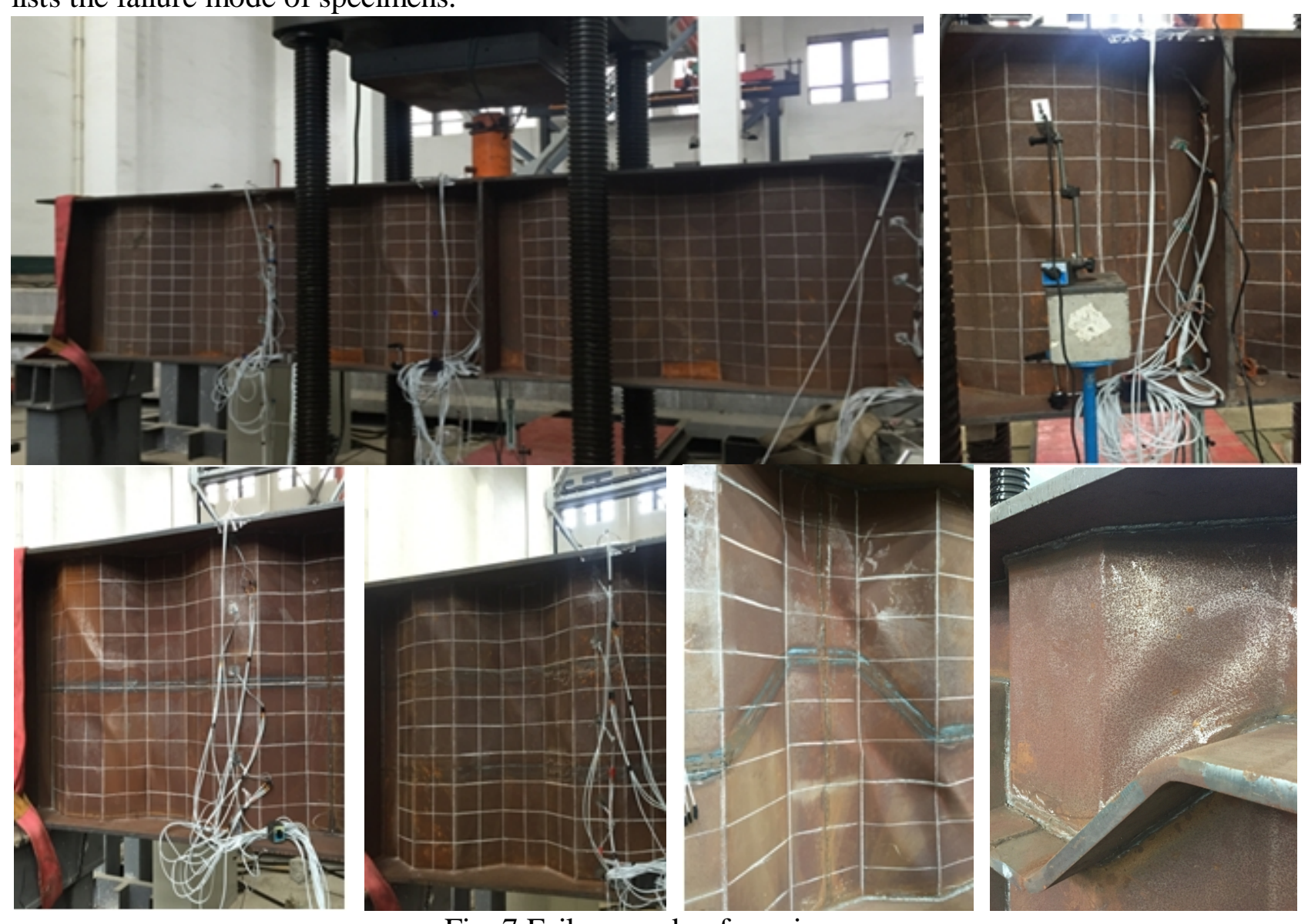

Fig. 7 Failure mode of specimens

Table 1 Failure mode of specimens

\begin{tabular}{lccccc}
\hline Specimens & GCW & SGCW1 & SGCW2 & CSGCW1 & CSGCW2 \\
\hline $\begin{array}{l}\text { Failure } \\
\text { mode }\end{array}$ & Global & Global & Global & Global & Local \\
& buckling & buckling & buckling & buckling & buckling \\
\hline
\end{tabular}

GCW with no longitudinal stiffeners tended to global buckling and failure load was less; SGCW1 with one longitudinal stiffener also tended to global buckling, but the stiffener prevented the buckling to throughout the webs, SGCW2 with two longitudinal stiffeners had no this function; CSGW1 with one corrugated longitudinal stiffener tended to global buckling; CSGCW2 with two corrugated longitudinal stiffeners had different failure mode: local buckling.

\section{Experimental Result Analysis}

Through the experimental phenomena and experimental data analysis, measurement point is selected to show load-stress and load-displacement relationship in Fig. 8 and Fig. 9. 
According to the Japanese planning manual ${ }^{[3,4,5]}$ about buckling strength, GCW is calculated and presented in Table 2.

$$
\begin{array}{ll} 
\begin{cases}\tau_{\mathrm{cr}}=\tau_{\mathrm{y}} & \lambda_{\mathrm{s}} \leq 0.6 \\
\tau_{\mathrm{cr}}=\tau_{\mathrm{y}}\left[1-0.614\left(\lambda_{\mathrm{s}}-0.6\right)\right] & 0.6 \leq \lambda_{\mathrm{s}} \leq \sqrt{2} \\
\tau_{\mathrm{cr}}=\tau_{\mathrm{y}} / \lambda_{\mathrm{s}}^{2} & \lambda_{\mathrm{s}} \geq \sqrt{2}\end{cases} \\
\lambda_{\mathrm{s}}=\sqrt{\tau_{\mathrm{y}} / \tau_{\mathrm{cr}}^{\mathrm{e}}} &
\end{array}
$$

Table 2 Shear strength $\tau_{\mathrm{cr}}$ according to formula (GCW)

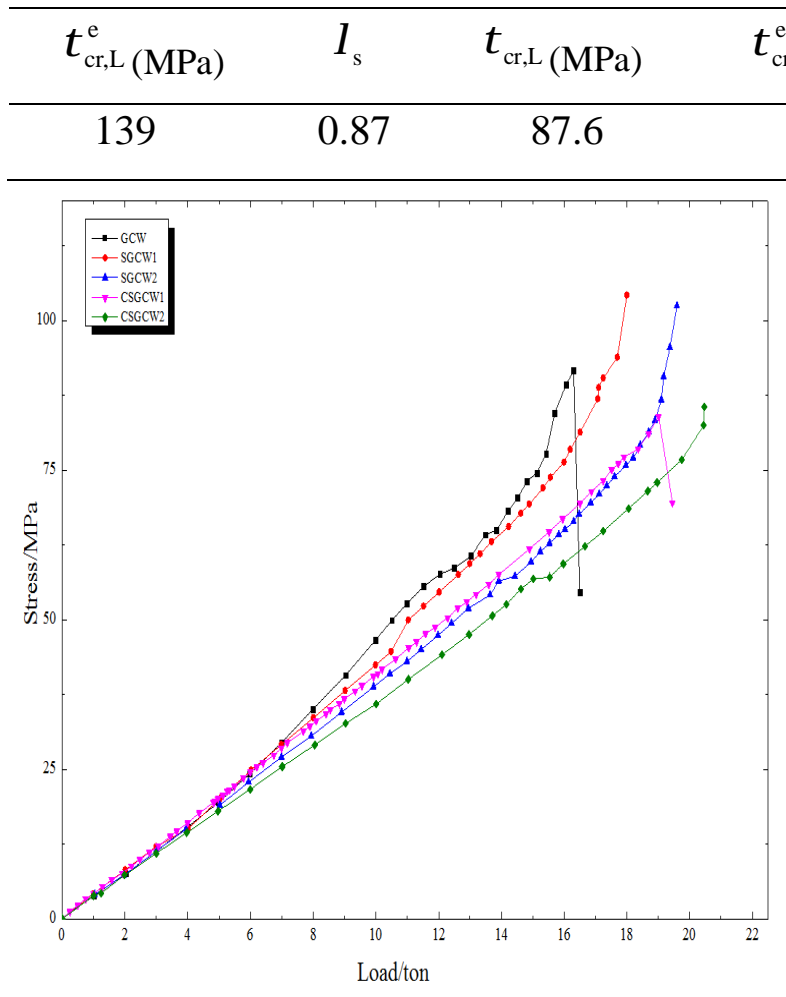

Fig. 8 Load-stress curves

\begin{tabular}{cccc}
$\tau_{\mathrm{cr}, \mathrm{G}}^{\mathrm{e}}(\mathrm{MPa})$ & $\lambda_{\mathrm{s}}$ & $\tau_{\mathrm{cr}, \mathrm{G}(\mathrm{MPa})}$ & $\tau_{\mathrm{cr}(\mathrm{MPa})}$ \\
\hline 2050 & 0.28 & 105 & 79.4
\end{tabular}

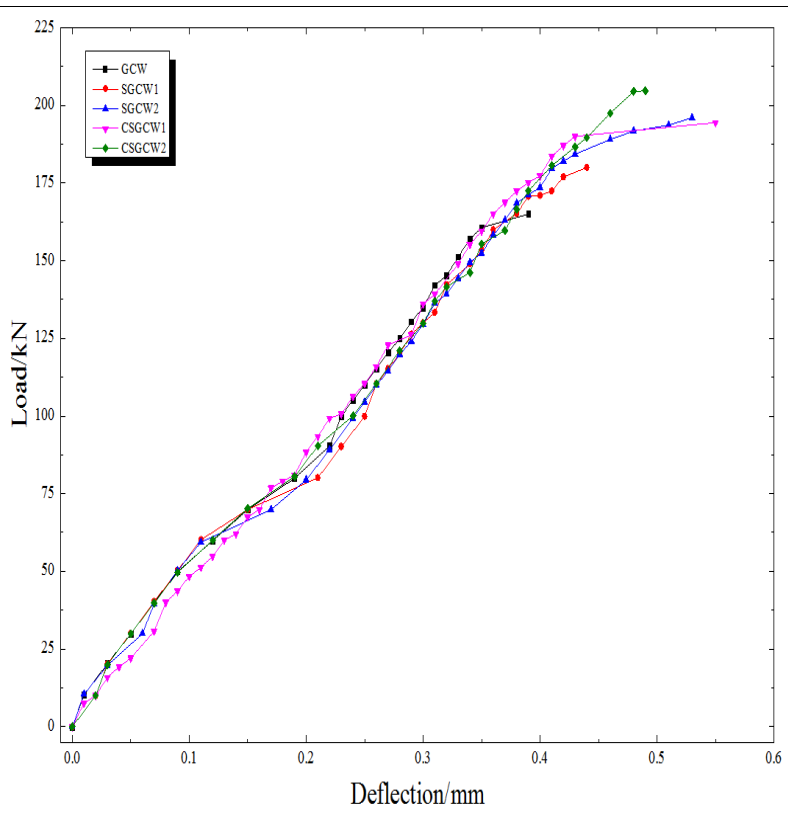

Fig. 9 Load-displacement curves

When the shear stress $\tau=80 \mathrm{MPa}$, the beam came to its buckling failure load according to Fig. 8 , this was consistent with the calculated value, different longitudinal stiffeners had no influence on the shear stress. But the buckling failure loads were different with each other shown in Table 3.

Table 3 Buckling failure load according to experimental

\begin{tabular}{cccccc}
\hline Specimens & GCW & SGCW1 & SGCW2 & CSGCW1 & CSGCW2 \\
\hline Buckling failure load $(\mathrm{kN})$ & 155 & 170 & 182 & 190 & 195 \\
\hline Improved compared to GCW $(\%)$ & & 9.6 & 17.4 & 22.6 & 25.8 \\
\hline
\end{tabular}

\section{Conclusions}

Five I-shaped steel beams with different longitudinal stiffeners have different buckling mode, CSGCW2 occurs local buckling and others tend to global buckling, it is due to the strong stiffeners which limit the development of buckling.

At the buckling failure load, the web stress of different longitudinal stiffeners is same, the shear strength still is assumed by the web, and the contribution of the stiffeners are limited.

The load of buckling failure increases with the different stiffeners, CSGCW2 can be increased about $25 \%$ compared with GCW, which is due to the strong connection between the longitudinal and transverse stiffeners. 
When the web is in buckling, the bearing capacity of the web is still increasing, this is post-buckling strength and can be used in design ${ }^{[6]}$.

\section{References}

[1] M. Elgaaly, R.W. Hamilton and A. Seshadri, in: Journal of Structural Engineering-ASCE. Vol.122 (4) (1996), p. 390.

[2] L. Leiva-Aravena. Buckling and strength of corrugated steel panels. Goteborg, Sweden: Chalmers University of Technology, 1987.

[3] The PC bridge with corrugated steel webs planning manual (1998), edited by Research association of composite structure with corrugated steel webs.

[4] S. P. Timoshenko and J. M. Gelle. Elastic stability theory. (Science Press, Beijing 1965), second edition.

[5] J. Yi, H. Gil and K. Youm, in: Engineering Structures. 30(6) (2008), p. 1659.

[6] R.G. Driver, H.H. Abbas and R. Sause, in: Journal of Structural Engineering-ASCE. Vol. 132(2) (2006), p. 195-203. 